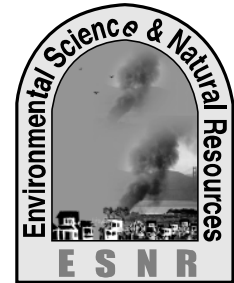

J. Environ. Sci. \& Natural Resources, 7(1): 257- 63, 2014

ISSN 1999-7361

\title{
Investigation of Water Quality Parameters Discharged from Textile Dyeing Industries
}

\author{
A. Munnaf ${ }^{1}$, M. S. Islam ${ }^{1 *}$, T. R. Tusher ${ }^{1}$, M. H. Kabir ${ }^{1}$ and M. A. H. Molla ${ }^{2}$ \\ ${ }^{1}$ Department of Environmental Science and Resource Management, \\ Mawlana Bhashani Science and Technology University, Tangail-1902, Bangladesh \\ ${ }^{2}$ Department of Bioenvironmental Sciences, \\ Bangabandhu Sheikh Mujibur Rahman Agricultural University, Gazipur-1706, Bangladesh.
}

\begin{abstract}
Rapid development of textile industry and direct deposition of the effluents into sewage networks produced disturbances in treatment processes and exert pollution loads on water bodies. The study was conducted to investigate the water quality parameters discharged from seven textile dyeing industries at Konabari in Gazipur region of Bangladesh during March to December, 2011, and also to evaluate the harmful effects of effluents on the surrounding environment. Emphasis was given on the investigation of important water quality parameters, which include temperature, $\mathrm{pH}$, total suspended solids (TSS), total dissolved solids (TDS), dissolved oxygen (DO), biochemical oxygen demand (BOD) and chemical oxygen demand (COD), along with the management techniques of effluents discharged from textile dyeing industries. The study depicted that the DO values were nil or below the standard values in all industries which was very alarming for environment. The concentrations of BOD, COD, TDS and TSS were very high which indicate the presence of water pollutants. The study was focused on the pollution implications of effluents from textile industries around the study area, because of the risk of human exposure and environmental degradation by these massive discharged effluents. The water quality deteriorated in dry season than the wet season and the surface water around the studied area was highly polluted due to the industrial activities and should totally avoid for human consumption without proper treatment. It is therefore recommended that the careless discharge of the effluents should be discouraged and appropriate management system should be taken immediately to reduce the water pollution for saving the environment.
\end{abstract}

Key words: Water quality, Waste water, Textile industry, Pollution

\section{Introduction}

Textile manufacturing sector is among the major industrial water users and distinguished by the use of raw materials which determines the volume of water required for the process as well as waste water generated. In this type of production, slashing, bleaching, mercerizing, and dyeing are the major water consumption activities as well as waste water generation. A lot of chemicals such as oil, grease, ammonia, sulfide, lead, color, hazardous pollutants, heavy metals and other toxic substances are added to the process for cleaning and dyeing purposes (Dara, 1993). The textile dyeing industries of Gazipur (Konabari) generate large amount of waste water on a regular basis which are being directly discharged into the surrounding channel, agricultural fields, irrigation channels, surface water; and these finally enter into Turag and Shitalakkhya River (Sultana et al., 2009). As a result, a considerable portion of the available water is being polluted by the textile effluents. The textile and dyeing effluents may cause alteration of the physical, chemical, and biological properties of aquatic environment by continuous change in temperature, odor, noise, turbidity etc that is harmful to public health, livestock, wildlife, fish, and other biodiversity (Islam et al., 2012a). The presence of dyes in surface and subsurface water is making them not only aesthetically objectionable but also causes many water borne diseases, viz. mucous membrane, dermatitis, perforation of nasal septum and severe irritation of respiratory tract (Sultana et al., 2009; Islam et al., 2012a).

The World Bank estimates that 17 to $20 \%$ of industrial water pollution comes from textile dyeing and treatment. They have also identified 72 toxic chemicals in our water solely from textile dyeing, 30 of which are cannot be removed (Islam et al., 2012a). As rivers are used directly or indirectly as dumps today, increasing growth of textile industries in Konabari at Gazipur are deteriorating the total environment as a whole. The water of the surrounding rivers that could be used for human consumption, industrial needs, land irrigation, fish production or recreation, is greatly contaminated by these toxic substances. Contamination to this aquatic system brings serious threat to the overall epidemic and socio-economic pattern inside (Islam et al., 2012a; Yahaya et al., 2009). This represents an appalling environmental problem for the clothing designers and other textile manufacturers. Thus, proper analysis is obviously needed to assess the pollution level for the protection of environment and natural resources. Such information is also important for the authorities to take proper action in preventing pollution of the area for the good health of the population. Considering these views in mind, the present study was conducted to determine the extent of pollution level of various physicochemical parameters concentrations in order to characterize the waste water of the textile dyeing industries. The objectives of the study were as: i) to analyze water quality discharged from textile dyeing industries, 
and ii) to evaluate the environmental impacts of textile dyeing industries waste water.

\section{Materials and Methods}

\section{Study area}

The study was conducted on seven textile industries at Konabari industrial area, shown in Fig. 1, in the district of Gazipur at a distance of about $50 \mathrm{~km}$ from the capital city, Dhaka, and $15 \mathrm{~km}$ from Gazipur town. The research was conducted through survey and experimental method. The name of the studied industries included Colombia Washing Plant Limited, Genesis Washing Limited, Fareast Knitting and Dyeing Industry Limited, Interstoff Apparels Limited, How Are You Textile Limited, Knit Asia Limited, Southeast Textile Limited.

\section{Sampling}

The study, carried out from March to December, 2011, included extensive ground surveys (by bus, rickshaw and on foot). Efforts were made to visit each studied industry for several time. Most of samples are collected from 10.00 am to $12.30 \mathrm{pm}$. It was possible to collect required sample from equalization tank because all the studied industries have effluent treatment plant. Simple Random sampling was used for the primary data collection. Then these data edited and rearranged in the form of qualitative and quantitative data. Some of the parameters require special equipment or knowledge and could not be easily tested. Effluent samples were collected from beginning of the equalization tank of each industry. The water samples were collected in various size plastic bottles. These bottles were washed with tap water followed by distilled water. Before sampling, bottles were rinsed
3 to 4 times with water to be sampled. Required reagents were used as preservative in these bottles. Collection and analysis of all samples were performed in both winter season and dry season. Preservation and transportation of samples is as important as their proper collection. The samples were collected carefully and transported to the laboratory as early as possible to avoid contamination.

\section{Sample analysis}

The various physicochemical parameters was studied in this study for determining and comparing water quality which included temperature, $\mathrm{pH}$, dissolved oxygen (DO), biochemical oxygen demand (BOD), chemical oxygen demand (COD), total dissolved solids (TDS) and total suspended solids (TSS). After collection, samples were transported to internal lab of A One Supply Company Limited and some are taken to central lab of Bangladesh centre for Advance Studies (BCAS) for analysis. The physicochemical parameters were analyzed in the Standard Methods for the examination of water and waste water. The temperature was measured by mercury thermometer. The $\mathrm{pH}$ was determined by potentiometric method, the DO was determined by winkler azide modification method, BOD was determined by bottle incubation for 5 days at $20^{\circ} \mathrm{C} \pm 1^{0} \mathrm{C}$, COD by open refluxed method, total dissolved solid (TDS) and total suspended solid (TSS) was measured by dry method at $103-105^{\circ} \mathrm{C}$. The analyzed data was used as primary data. Then the collected data were 'Tabulated' and 'coded'. The SPSS and SAS software was used for data analysis.

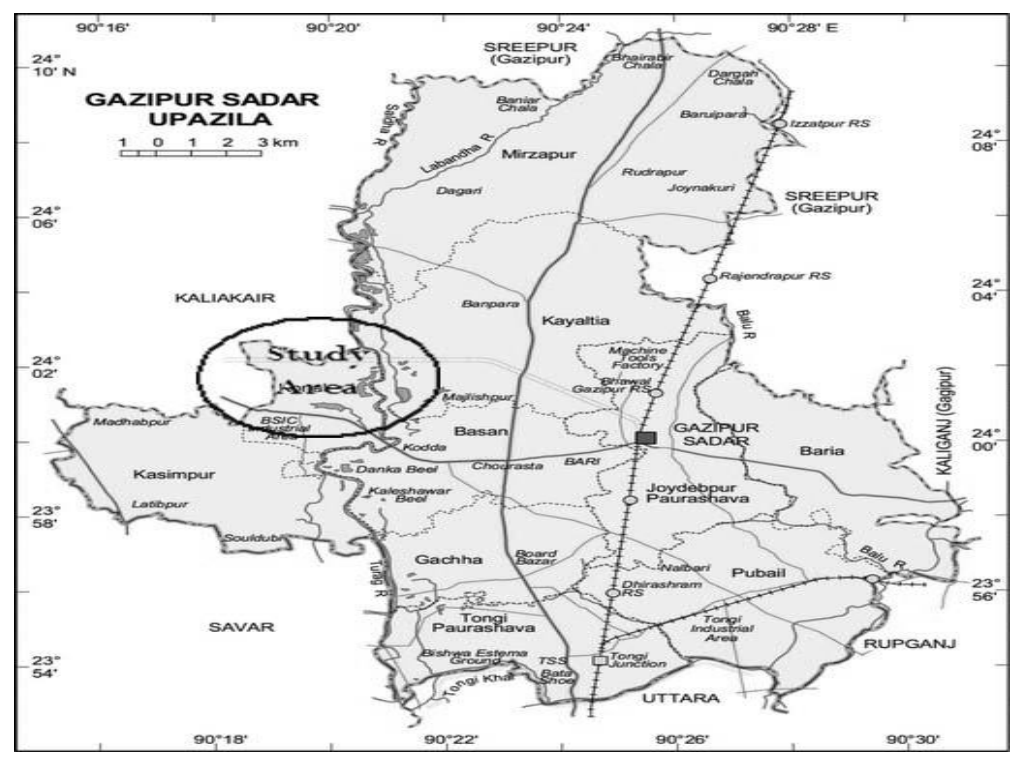

Fig. 1. Map showing the study area of Konabari industrial area (Banglapedia, 2012) 


\section{Results and Discussions}

Generally, the water quality discharged from different textile industries need to be properly monitored for better environmental protection. The average water quality discharged from seven different textile industries and standard limits in The Environment Conservation Rules (ECR, 1997) prescribed by Department of Environment (DoE), Bangladesh (Table 1).

Table 1. Quality of water discharged from the seven industries with DoE prescribed standard

\begin{tabular}{|c|c|c|c|c|c|c|c|c|c|}
\hline \multirow{6}{*}{$\begin{array}{c}\text { Water } \\
\text { Quality } \\
\text { Parameters }\end{array}$} & \multirow[t]{6}{*}{ Season } & \multicolumn{7}{|c|}{ Name of the Industry } & \multirow{2}{*}{$\begin{array}{c}\text { Banglades } \\
\mathrm{h}\end{array}$} \\
\hline & & Colombia & Genesis & Fareast & Interstof & How Are & Knit & Southeast & \\
\hline & & Washing & Washin & Knitting & $\mathrm{f}$ & You & Asia & Textile & Standards \\
\hline & & Plant & $\mathrm{g}$ & and Dyeing & Apparel & Textile & Textile & Limited & $(\mathrm{ECR}$ \\
\hline & & Limited & Limited & Industry & $\mathrm{S}$ & Limited & Limite & & 1997) \\
\hline & & & & Limited & Limited & & $\mathrm{d}$ & & \\
\hline \multirow{2}{*}{$\begin{array}{c}\text { Temperatur } \\
\mathrm{e} \\
\left({ }^{\circ} \mathrm{C}\right)\end{array}$} & Rainy & 43 & 43.5 & 45.1 & 39 & 42.1 & 38 & 41 & 40 \\
\hline & Winter & 45 & 47 & 46 & 43 & 45.7 & 34.8 & 44.2 & \\
\hline \multirow[t]{2}{*}{$\mathrm{pH}$} & Rainy & 9.5 & 10 & 10.5 & 9.1 & 8.9 & 9.5 & 9.2 & $6.5-9.0$ \\
\hline & Winter & 9.9 & 10.2 & 9.9 & 10.5 & 10.4 & 9.2 & 10.5 & \\
\hline \multirow{2}{*}{$\begin{array}{c}\text { TSS } \\
(\mathrm{mg} / \mathrm{l})\end{array}$} & Rainy & 120 & 115 & 330 & 120 & 310 & 195 & 210 & 100 \\
\hline & Winter & 100 & 110 & 390 & 130 & 377 & 215 & 190 & \\
\hline \multirow{2}{*}{$\begin{array}{c}\text { TDS } \\
(\mathrm{mg} / \mathrm{l})\end{array}$} & Rainy & 4247 & 5015 & 6412 & 5540 & 5240 & 5800 & 5410 & 2100 \\
\hline & Winter & 4418 & 5425 & 6700 & 5730 & 5575 & 6123 & 5614 & \\
\hline \multirow{2}{*}{$\begin{array}{c}\mathrm{DO} \\
(\mathrm{mg} / \mathrm{l})\end{array}$} & Rainy & 1.2 & 0.6 & 1.4 & 0.8 & 0.00 & 1.9 & 1.3 & $4.5-8.0$ \\
\hline & Winter & 0.11 & 0.00 & 0.08 & 0.00 & 0.00 & 0.02 & 0.00 & \\
\hline \multirow{2}{*}{$\begin{array}{l}\text { BOD } \\
(\mathrm{mg} / 1)\end{array}$} & Rainy & 498 & 480 & 390 & 420 & 471 & 392 & 485 & 150 \\
\hline & Winter & 515 & 507 & 403 & 445 & 495 & 478 & 503 & \\
\hline \multirow{2}{*}{$\begin{array}{l}\text { COD } \\
(\mathrm{mg} / \mathrm{l})\end{array}$} & Rainy & 1310 & 1590 & 1184 & 1200 & 1500 & 1462 & 1194 & 200 \\
\hline & Winter & 1360 & 1650 & 1216 & 1120 & 1634 & 1531 & 1184 & \\
\hline
\end{tabular}

Temperature can exert great control over aquatic communities. If the overall water body temperature of a system is altered, an aquatic community shift can be expected. In water above $30^{\circ} \mathrm{C}$, a suppression of all benthic organisms can be expected. The water temperature of studied industries ranges from $38-45.1^{\circ} \mathrm{C}$ and $34.8-47^{\circ} \mathrm{C}$ in rainy and winter season, respectively (Table 1 ). The variation in temperature of studied industries between winter and rainy season is shown in Fig. 2 . During rainy season, the highest temperature of $45.1^{\circ} \mathrm{C}$ was observed in Fareast Knitting and Dyeing Industry Limited, while the highest temperature of $47^{\circ} \mathrm{C}$ was found in Genesis Washing Limited during winter season (Fig. 2).

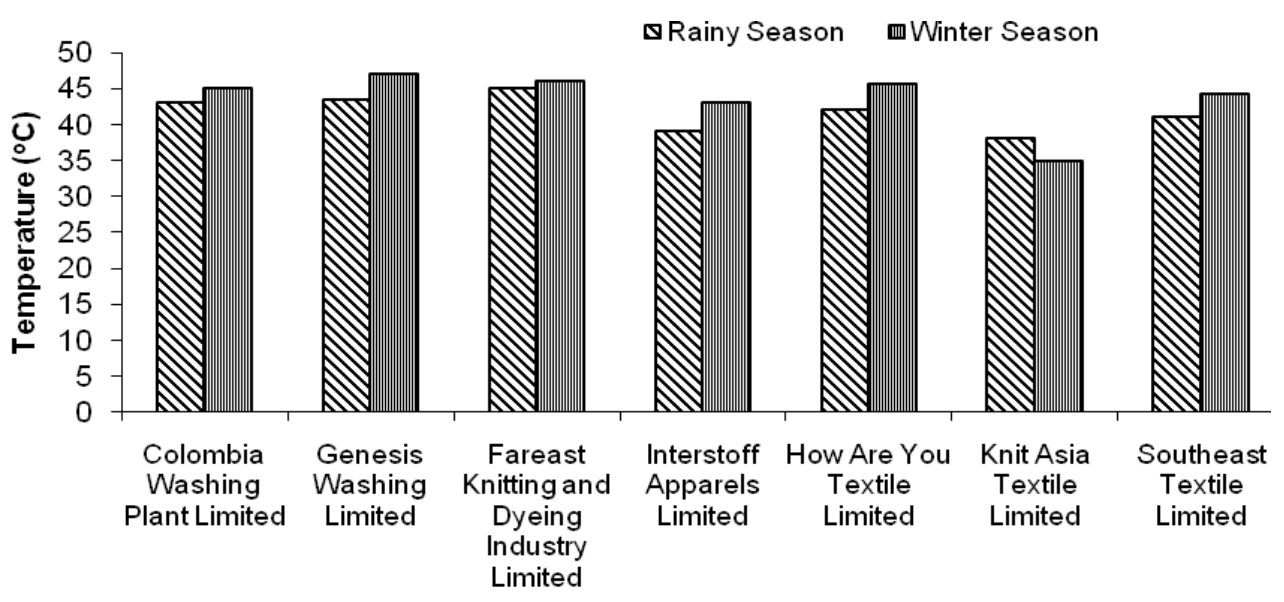

Name of the industries

Fig. 2. Comparison of temperature between rainy and winter season 
The $\mathrm{pH}$ is an indicator of the existence of biological life as most of them thrive in a quite narrow and critical $\mathrm{pH}$ range. The $\mathrm{pH}$ of water discharged from these industries ranges from 8.9-10.5 and 9.2-10.5 during rainy and winter season, respectively (Table 1). That is the discharged water was alkaline. The variation in $\mathrm{pH}$ of these seven industries between rainy and winter season is shown in Fig. 3. The highest $\mathrm{pH}$ of 10.5 was observed in Fareast Knitting and Dyeing Industry Limited during rainy season and in Interstoff Apparels Limited and Southeast Textile Limited during winter season (Fig. 3).

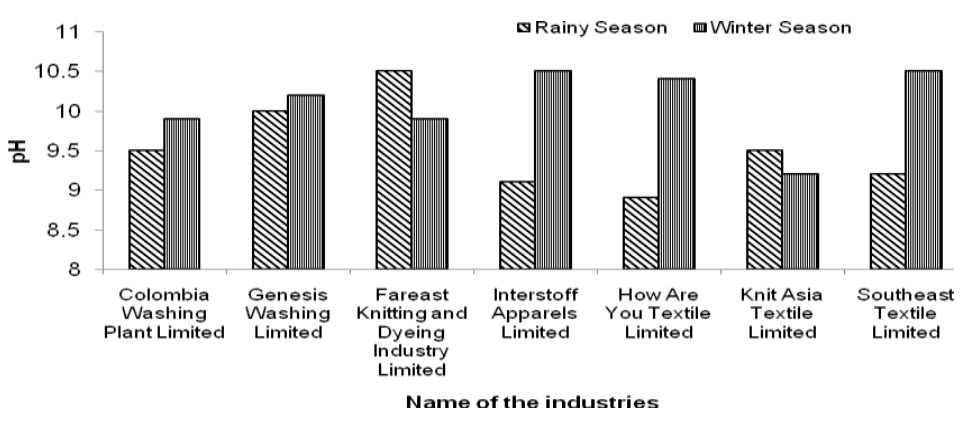

Fig. 3. Comparison of $\mathrm{pH}$ between rainy and winter season

The total suspended solids (TSS) value of studied industries water ranges from 115-330 and 100-390 $\mathrm{mg} / \mathrm{l}$ in rainy and winter season, respectively (Table 1). The variation in TSS of these seven industries between rainy and winter season is shown in Fig. 4.
The highest TSS of 330 and $390 \mathrm{mg} / \mathrm{l}$ was observed in Fareast Knitting and Dyeing Industry Limited during rainy and winter season, respectively (Fig. 4).

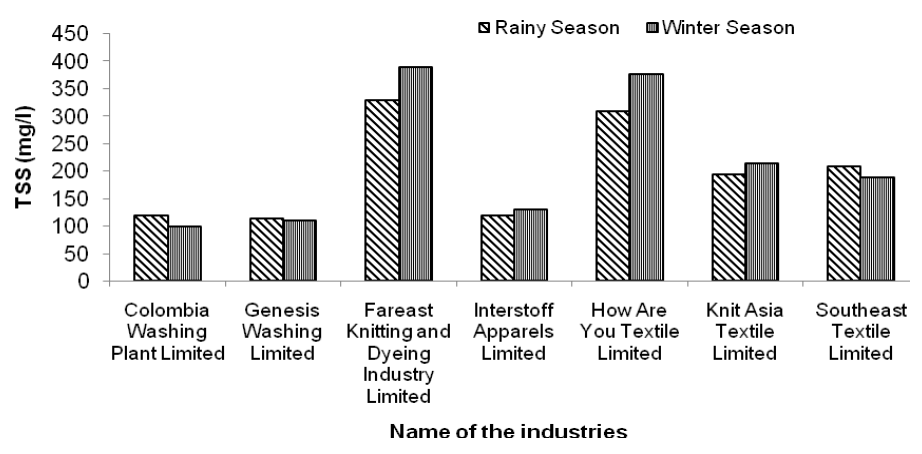

Fig. 4. Comparison of TSS between rainy and winter season

The total dissolved solids (TDS) concentrations varied from 4247-6700 mg/l, while the Bangladesh standard value is $2100 \mathrm{mg} / \mathrm{l}$ (Table 1). The comparison of TDS concentrations between rainy and winter is shown in Fig. 5. The highest TDS of 6412 and $6700 \mathrm{mg} / \mathrm{l}$ was observed in Fareast Knitting and Dyeing Industry Limited during rainy and winter season, respectively (Fig. 5).

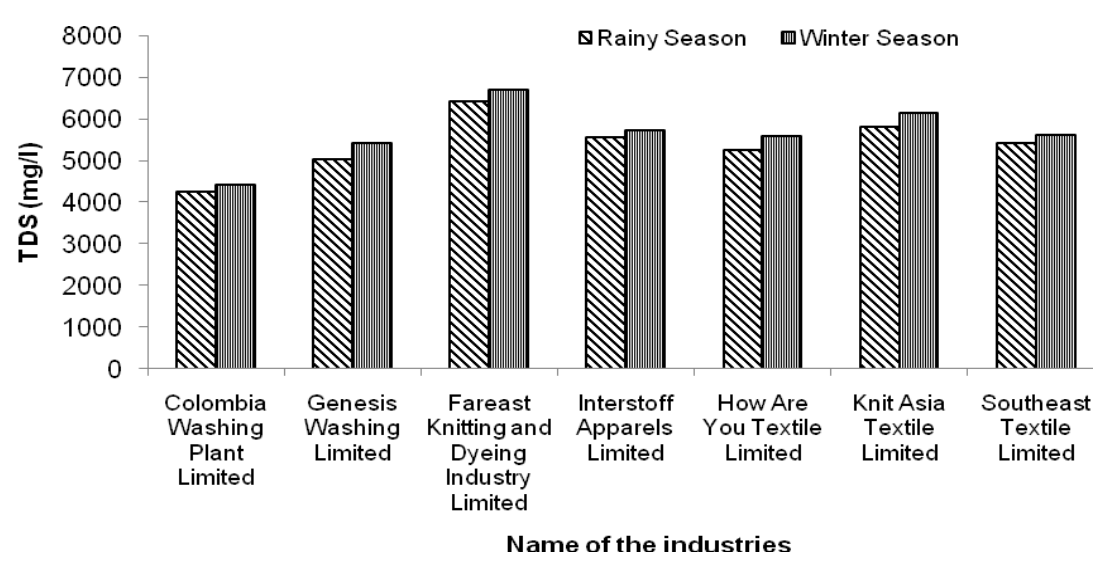

Fig. 5. Comparison of TDS between rainy and winter season 
The dissolved oxygen (DO) is an essential water quality parameter for aquatic life. A low DO (less than $2 \mathrm{mg} / \mathrm{l}$ ) would indicate poor water quality and thus would have difficulty in sustaining much sensitive aquatic life. The observed DO content of water discharged from studied industries in rainy and winter seasons are shown in Table 1. Almost all of the studied water samples contain DO concentrations of less than $1 \mathrm{mg} / \mathrm{l}$ or nil (Table 1 ). The variation of DO concentrations between rainy and winter season is shown in Fig. 6. The highest DO of 1.9 and $0.11 \mathrm{mg} / \mathrm{l}$ was observed in Knit Asia Textile Limited and Colombia Washing Plant Limited during rainy and winter season, respectively (Fig. 6).

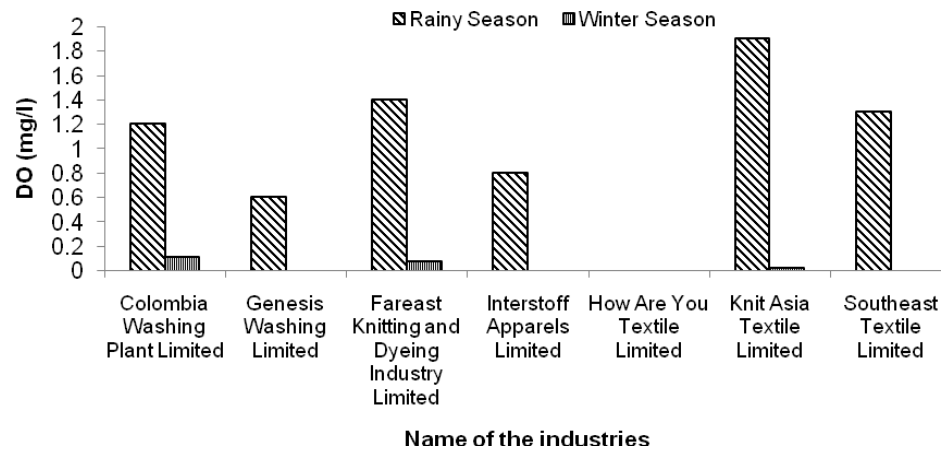

Fig. 6. Comparison of DO between rainy and winter season

The biological oxygen demand (BOD) concentrations varied from $390-515 \mathrm{mg} / \mathrm{l}$, while the Bangladesh standard value is $150 \mathrm{mg} / \mathrm{l}$ (Table 1). The comparison of BOD concentrations between rainy and winter is shown in Fig. 7. The highest BOD of 498 and $515 \mathrm{mg} / \mathrm{l}$ was observed in Colombia Washing Plant Limited during rainy and winter season, respectively (Fig. 7). The chemical oxygen demand (COD) values ranged from 11841590 and 1120-1650 mg/l during the rainy and winter season, respectively (Table 1). The variation of COD concentrations between rainy and winter season is shown in Fig. 8. The highest COD of 1590 and $1650 \mathrm{mg} / \mathrm{l}$ were observed in Genesis Washing Limited during rainy and winter season, respectively (Fig. 8).

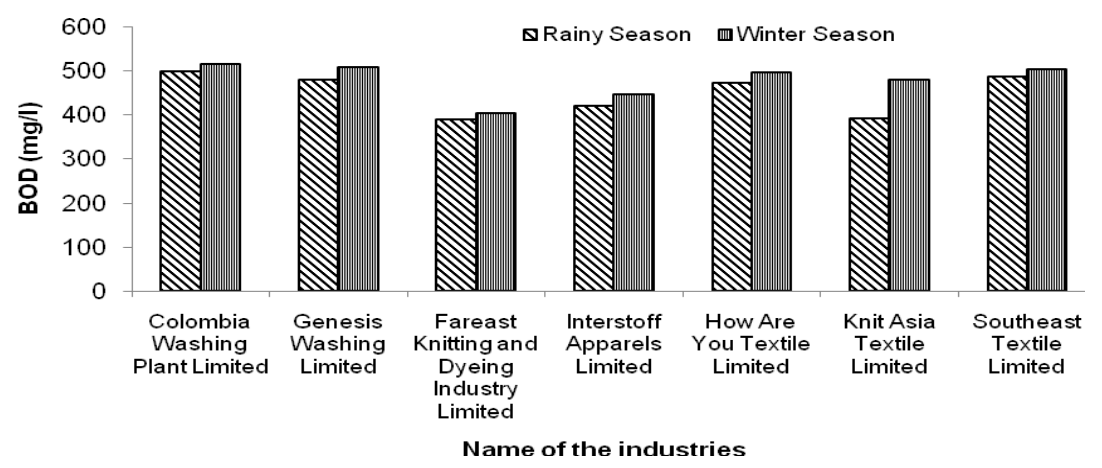

Fig. 7. Comparison of BOD between rainy and winter season

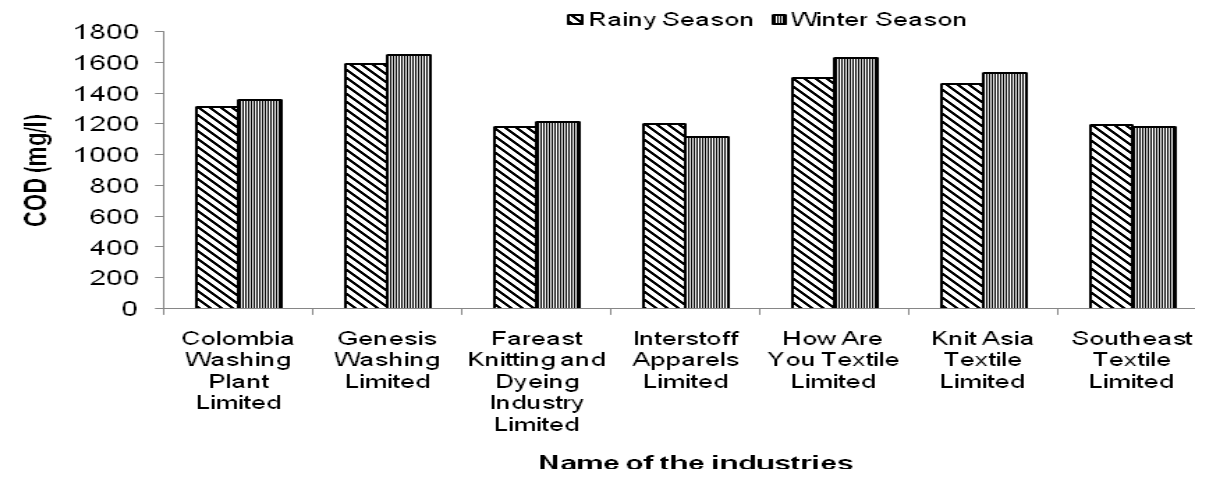

Fig. 8. Comparison of COD between rainy and winter season 
The comparison of different studied water quality parameters has been made with the standard values of industrial waste water prescribed by DoE, Bangladesh. It is clearly evident from the study that the waste water quality in the Gazipur region did not support the standard for industrial waste water of DoE, Bangladesh. The $\mathrm{pH}$ and TDS of discharged water was greatly higher than the standard levels. The higher TDS and TSS are not favorable for the aquatic environment. The maximum TDS value of $400 \mathrm{ppm}$ is permissible for diverse fish production (Chhatwal, 1998). The concentration of the dissolved and suspended solids may cause the water to be corrosive, salty or brackish tase, result in scale formation, and interfere and decrease efficiency of hot water heaters and many contain elevated levels of ions that are above the Primary or Secondary Drinking Water Standards, such as: an elevated level of nitrate, arsenic, aluminum, copper, lead, etc. Water that contains more than $1000 \mathrm{ppm}$ of dissolved solids usually contains minerals that give it a distinctive taste or make it unsuitable for human consumption (Irshad et al., 2011). High TSS and TDS detected could be attributed to the high color from the various dyestuffs being used in the textile mills and they may be major sources of the heavy metals. Increased heavy metals concentrations in river sediments could increase suspended solids concentrations. During the dry season, the occasional dust re-suspension could introduce these metals into the atmosphere along with the particulates. With this, they could constitute health problems in form of air pollution. Some of the vapors formed above have great potential to nucleate thus becoming particulate problem to the environment. In addition to these are the products of reactions between some of the chemicals present in the effluents which may be toxic to the environment. Removal of the pollutants from these effluents is the only sure way of safer environment and this can be achieved by treatment to required level.

The DO content was significantly lower and in sometimes was zero, while the Bangladesh standard is 4.5-8.0 mg/l. Besides these, the excessive amount of BOD and COD concentrations were found, which is an ultimate evidence of localized pollution. The textile dyeing industries of Gazipur generate large amount of waste water on a regular basis which are being directly discharged into the surrounding channel, agricultural fields, irrigation channels, surface water; and these finally enter into Turag river (Islam et al., 2012a). Thus, a lower amount of DO was observed in most of the downstream parts of Turag River (Islam et al, 2012b). The most important measure of water quality is the DO content. The low level of DO recorded could result in the non maintenance of conditions favorable to the aerobic organisms. This could lead to anaerobic organisms taking over with the resultant creation of conditions making the water body uninhabitable to gill-breathing aquatic organisms. Hydrogen sulphide is formed under conditions of deficient oxygen in the presence of organic materials and sulphate (WHO, 1996). This could be a possible reason for the high sulphide measured in the effluents analyzed. The high levels of BOD are indications of the pollution strength of the wastewaters. They also indicate that there could be low oxygen available for living organisms in the wastewater when utilizing the organic matter present. High COD levels imply toxic condition and the presence of biologically resistant organic substances. Unpolluted waters typically have COD values of 200 or less. The COD values denoted that the water body had a higher chemical concentration (Chapman, 1996).

Organisms are very susceptible to acids and bases. The effects of water pollution are varied and depend on what chemicals are dumped and in what locations. The water is filled with toxic waste and sewage, and routinely receives more waste when rainfall pushes it into the water bodies. Many bodies of water near industrial areas are highly polluted; this is due to chemicals legally or illegally dumped by industries. The main problem caused by water pollution is that it kills life that inhabits water-based ecosystems. Dead fish, birds, dolphins, and many other animals often wind up on beaches, killed by pollutants in their habitat. Pollution disrupts the natural food chain as well. Eventually, humans are affected by this process as well. People can get diseases by eating food that has been poisoned. Ecosystems can be severely changed or destroyed by water pollution. Many areas are now being affected by careless industrial pollution, and this pollution is coming back to hurt humans. The result of the study concluded that the water quality of the study area is fully polluted and the impacts for the degradation are causing many devastating harms. Some of the area is more vulnerable to pollution for different reasons. The negative impacts from textile mills effluents could be felt as far as all the regions covered by the river basin, the main receptor of these effluents.

High heavy metal concentration has found in these rivers attributed this to industries. The textile industries which are some of the most active in the city could be one of the sources and this confirms the potential dangers associated with high copper levels detected in the effluents analyzed. Detected effluents' parameters could form gaseous emission and particulates the potential threat they pose to the environment especially around Shitalakhma, Turag and Buriganga river basins calls for stringent control measure (Islam et al., 2011). Three million gallons textile waste water poured into river, polluting an area one-fourth the total size and this amount of spill can killed around 200,000 to 250,000 fish. If no attention is paid to control or prevent the degradation of water quality the area will be suffer from safe water and loss of biodiversity within short period of time. So if we don't take immediate steps for the prevention of the degradation of water quality in the near future the water of the study area will be damage.

\section{Conclusion}

The study concluded that the volume of waste water discharged from the studied industries often exceeds acceptable standards. The textile dyeing industries in Gazipur area discharge large quantities of effluent composed of various physicochemical 
pollutants at significant higher level than standard value of DoE except some industries which have authentic waste water treatment plants. From the findings of the study, it can be easily said that the water of Turag and Shitalakkhya River is getting highly polluted by the effluent discharged by the dyeing industries of the study area. The concentration of these pollutants is increasing in an alarming rate with the increasing number of textile dyeing industries. It is highly destructive for aquatic life as well as human life. If being directly discharged without being treated, it will bring serious harm to the ecological environment. Thus, the following recommendations should be followed for ensuring a better industrial water quality for the present and future generation: i) reduce water pollution by targeted intervention, promote public awareness and participations, rectify market and policy failures, ii) develop environmentally sound sector policy, develop flexible and enforceable environmental legislation and standards, develop and transfer environmentally sound technology, iii) establish appropriate effluent treatment plant (ETP) in each industry and foster an integrated approach to recycle and reuse industrial waste water, iv) it should be mandatory that industries construct and then regularly and efficiently operate their ETPs and monitor their effluents to keep them within the standards set by law, v) DoE should seek to actively work with and inform local government at Union and Upazila levels of the issues and how local government can use its powers to minimize pollution.

\section{Acknowledgements}

The authors are grateful to the personals of the A One Supply Company Limited, and the Bangladesh Centre for Advance Studies (BCAS) for their kind cooperation during the study period.

\section{References}

Banglapedia. 2012. National Encyclopedia of Bangladesh. Asiatic Society of Bangladesh.

Chapman, D. 1996. Water Quality Assessment: A guide to the use of biota, sediments and water in environmental monitoring. $2^{\text {nd }}$ edition, UNESCO/ WHO/ UNEP.

Chhatwal, G.R. 1998. Encyclopedia of Environmental Biology. Anmol Publication Private Ltd., New Delhi, India, 287-301.
Dara, S.S. 1993. A text book of environmental chemistry and pollution control. $1^{\text {st }}$ edition, S. Chand and Company Ltd, Ramnagar, New Delhi, India, 87-92.

ECR (Environment Conservation Rules). 1997. Schedule 10, Rule 13 (Bangladesh Gazette of 28 August 1997) (Own authentic translation from original Bengali), 3132 - 3134.

Irshad, M.; Malik, N.; Khan. T. and Faridullah, M. 2011. Effect of solid waste on heavy metal composition of soil and water at NathiagaliAbbottabad. Department of Environmental Sciences, COMSATS Institute of Information Technology, Abbottabad. Pakistan.

Islam, M.M.; Mahmud, K.; Faruk, O. and Billah, M.S. 2011. Textile dyeing industries in Bangladesh for sustainable development. International Journal of Environmental Science and Development, 2(6): 427-428.

Islam, M.S.; Chowdhury, M.A.H.; Billah, M.M.S.; Tusher, T.R. and Sultana, N. 2012a. Investigation of effluent quality discharged from the textile industry of Purbani group, Gazipur, Bangladesh and its management. Bangladesh Journal of Environmental Science, 23: 123-130.

Islam, M.S.; Tusher, T.R.; Mustafa, M. and Mahmud, S. 2012b. Effects of solid waste and industrial effluents on water quality of Turag River at Konabari industrial area, Gazipur, Bangladesh. Journal of Environmental Science \& Natural Resources, 5(2): 213-218.

Sultana, M.S.; Islam, M.S.; Saha, R. and Mansur, M.A.A. 2009. Impact of the effluents of textile dyeing industries on the surface water quality inside DND embankment, Narayanganj. Bangladesh J. Sci. Indus. Res., 44(1): 66.

WHO (World Health Organization). 1996. Guidelines for drinking water quality. Volume 2: Health criteria and other supporting information, World Health Organization, Geneva, Switzerland.

Yahaya, M.I.; Mohammad, S. and Abdullahi, B.K. 2009. Seasonal variations of heavy Metals concentration in Abattoir dumping site soil in Nigeria. Journal of Applied Sciences for Environmental Management, 13 (4): 9-13. 